Original Research Paper

\title{
Thermal Characterization of an Eco Concrete Based on Lateritic Gravel, Millet Pods and Cement
}

\author{
${ }^{1,2,3}$ Djossou Ayihaou Armand, ${ }^{3}$ Doko Kouandété Valéry, \\ ${ }^{3}$ Wade Doukago Yacoubou Soumanou, ${ }^{3}$ Michozounnou Bénoît and ${ }^{1}$ Vianou Antoine \\ ${ }^{1}$ Laboratory of Materials Thermophysical Characterization and Energy Appropriation (Labo-CTMAE) \\ -Polytechnic School of Abomey-Calavi (EPAC), 01 BP 2009 - Cotonou (Benin) \\ ${ }^{2}$ National Higher Institute of Industrial Technology (INSTI) of Lokossa, PB 133 - Lokossa (Benin) \\ ${ }^{3}$ Laboratory of Applied Energetic and Mechanics (LEMA)-Polytechnic School of Abomey-Calavi (EPAC), \\ 01 BP : 2009 - Cotonou (Benin)
}

\section{Article history}

Received: 11-05-2021

Revised: 19-06-2021

Accepted: 22-06-2021

Corresponding Author: Djossou Ayihaou Armand Laboratory of Thermophysical Characterization of Materials and Energy Appropriation (Labo-CTMAE)-Polytechnic School of Abomey-Calavi (EPAC), 01 BP 2009 - Cotonou (Benin)

Email: ayihaou@yahoo.fr

\begin{abstract}
To simultaneously meet the need of thermal confort and living environment protection, vegetable biomass valorisation in building sector is of particular importance. In this context, the main objective of this study is to produce a lightweight composite concrete based on millet pods and lateritic gravel with a cement matrix for use in buildings to help improve thermal comfort and protect environment. To achieve this, the composite formulation with $250 \mathrm{~kg} \cdot \mathrm{m}^{-3}$ cement dosage and an 0.8 water to cement ratio was used to manufacture two type test specimens of $(4 \times 4 \times 16) \mathrm{cm}^{3}$ dimensions for porosity tests and $(4 \times 4 \times 5) \mathrm{cm}^{3}$ for thermal tests with a millet pod rate varying from 0 to $6 \%$ with a step of $2 \%$. Average thermophysical characteristics of 5 tests carriesd out over 5 days, namely: Thermal conductivity, thermal diffusivity, thermal effusivity, thermal phase and damping, were experimentally measured using fluxmetric method similar to that of mini hot plate method with two Peltier elements as fluxmeters. Results obtained showed that for $0,2,4$ and $6 \%$ millet pods dosage, thermal conductivity values obtained are respectively $1.18 \mathrm{~W} \cdot \mathrm{m}^{-1} \cdot \mathrm{K}^{-1}, 0.74 \mathrm{~W} \cdot \mathrm{m}^{-1} \cdot \mathrm{K}^{-1}, 0.63$ $\mathrm{W} \cdot \mathrm{m}^{-1} \cdot \mathrm{K}^{-1}$ and $0.61 \mathrm{~W} \cdot \mathrm{m}^{-1} \cdot \mathrm{K}^{-1}$, i.e., a reduction of $93.44 \%$. For same millet pod dosage, thermal effusivity values are $2157.33 \mathrm{~J} \cdot \mathrm{m}^{-2} \cdot \mathrm{K}^{-1} \cdot \mathrm{s}^{-0.5}, 1236.34$ $\mathrm{J} . \mathrm{m}^{-2} \cdot \mathrm{K}^{-1} \cdot \mathrm{s}^{-0.5}, 946.03 \mathrm{~J} \cdot \mathrm{m}^{-2} \cdot \mathrm{K}^{-1} \cdot \mathrm{s}^{-0.5}$ and $775.04 \mathrm{~J} \cdot \mathrm{m}^{-2} \cdot \mathrm{K}^{-1} \cdot \mathrm{s}^{-0.5}$, i.e., a reduction of $64.07 \%$. On the other hand, it was observed $3.00 \cdot 10^{-7} \mathrm{~m}^{2} \cdot \mathrm{s}^{-1}, 3.56 \cdot 10^{-7} \mathrm{~m}^{2} \cdot \mathrm{s}^{-1}$, $4.47 .10^{-7} \mathrm{~m}^{2} . \mathrm{s}^{-1}$ and $6.25 .10^{-7} \mathrm{~m}^{2} . \mathrm{s}^{-1}$, i.e., an increase of $108.33 \%$ for thermal diffusivity. With regard to dynamiquc thermal characteristics, it was obtained an increase from 5.43 to $13.18 \%$ for thermal damping and, from 61.00 to $84.20 \mathrm{~min}$ for thermal phase. Through on the one hand, thermal conductivity and effusivity decrease and on the other hand, thermal damping and phase shift increase, it is retained that characterized eco-concrete should contribute to thermal losses limitation, energiy saving and improved thermal comfort.
\end{abstract}

Keywords: Eco-Concrete, Biomass, Fluxmetric Method, Millet Pods, Thermal Properties

\section{Introduction}

This study is part of research for ligthweight ecological materials with better insulating power, obtained by replacing all or part of mineral aggregates with mainly vegetable biomass. In this context, Baley (2005) showed recovery of plant fibers allows environmental impacts reduction compared to conventional composites since they are renewable raw materials, biodegradable, neutral with respect to $\mathrm{CO}_{2}$ emissions and requiring little energy to be produced (Baley, 2005). The work of Aymerich et al. (2012); Röhlen et al., (2013) had shown that earth is one of materials that limit building environmental impacts while providing pleasant thermal comfort.

Plant fibers and especially waste introduction into laterite is currently the subject of numerous studies in order to have a light material with better thermal characteristics (Dewulf, 
2015). This formulation not only prevents material cracking but also improves structure stability and its resistance to weathering (Röhlen et al., 2013).

Thus, our previous work in (2014) had shown that with a sawdust dosage between $2 \%$ and $4 \%$, laterite satabilized with $4 \%$ cement offers a thermal conductivity between $0.63 \mathrm{~W} \cdot \mathrm{m}^{-1} \cdot \mathrm{K}^{-1}$ and $0.59 \mathrm{~W} \cdot \mathrm{m}^{-1} \cdot \mathrm{K}^{-1}$, while it varies from $0.65 \mathrm{~W} \cdot \mathrm{m}^{-1} \cdot \mathrm{K}^{-1}$ to $1.35 \mathrm{~W} \cdot \mathrm{m}^{-1} \cdot \mathrm{K}^{-1}$ with water content without sawdust (Djossou et al., 2014).

With a mixture of a lot of soil and little straw, a thermal conductivity of $1.05 \mathrm{~W} \cdot \mathrm{m}^{-1} \cdot \mathrm{K}^{-1}$ was obtained with a density of $1400 \mathrm{~kg} \cdot \mathrm{m}^{-3}$. Conversely, a thermal conductivity between $0.12 \mathrm{~W} \cdot \mathrm{m}^{-1} \cdot \mathrm{K}^{-1}$ and $0.15 \mathrm{~W} \cdot \mathrm{m}^{-1} \cdot \mathrm{K}^{-1}$ was obtained with a density ranging from $300 \mathrm{~kg} \cdot \mathrm{m}^{-3}$ to $400 \mathrm{~kg} \cdot \mathrm{m}^{-3}$ (AsTerre, 2021; Phung, 2018).

It has also been shown that an optimal dosage of $4 \%$ cow dung makes it possible to obtain a thermal effusivity between $1608.53 \mathrm{~J} \cdot \mathrm{m}^{-2} \cdot \mathrm{K}^{-1} \cdot \mathrm{s}^{-0.5}$ and $2300.78 \mathrm{~J} \cdot \mathrm{m}^{-2} \cdot \mathrm{K}^{-1} \cdot \mathrm{s}^{-0.5}$ and a thermal conductivity varying from $0.63 \mathrm{~W} \cdot \mathrm{m}^{-1} \cdot \mathrm{K}^{-1}$ to $0.71 \mathrm{~W} \cdot \mathrm{m}^{-1} \cdot \mathrm{K}^{-1}$ for laterite stabilized with 0 to $12 \%$ cement (Djossou et al., 2017/18). With $4 \%$ of cow dung, the highest dry density obtained is $1699 \mathrm{~kg} \cdot \mathrm{m}^{-3}$ and the lowest is 1478 kg.m ${ }^{-3}$ (Djossou et al., 2017/18).

One of these work shortcoming lies in failure to take into account porosity influence on thermophysical characteristics of tested materials. Furthermore, the tests were carried out under laboratory condtions with certain assuptions difficult to meet in pratice. In this study context, tests carried out under real operating conditions of material, taking porosity influence into account, using fluxmetric method similar to that of mini hot plate method with two Peltier elements as fluxmeters.

\section{Materials}

\section{Laterite}

Figure 1 shows granulometric analysis curve on lateritic gravel used in this study. It was taken from a quarry located Attotinga, Agbanou district in Allada municipality. The improved laterite with cement is stronger than naturally occurring laterite or litho stabilized laterite.

\section{Millet Pods Fibers}

The millet pods used come from northern Benin in Alibori, Ségbana department, where millet is used to make a popular local drink (Tchoukoutou). Figure 2 and 3 show respectively fibers texture and millet pods granulometric analysis curve. The previously weighed millet pods are first pre-wetted during $24 \mathrm{~h}$. They are then spread over a sieve to remove excess water. In this way, we prevent the water required for cement hydration from being absorbed by material.
Table 1: Cement physical characteristics (NOCIBE laboratory, NF EN 197-1: 2012)

\begin{tabular}{lr}
\hline Apparent density $\left(\mathrm{kg} \cdot \mathrm{m}^{-3}\right)$ & 1073 \\
\hline Absolute density $\left(\mathrm{kg} \cdot \mathrm{m}^{-3}\right)$ & 3010.00 \\
Start of setting & $3 \mathrm{~h} 05$ \\
End of setting & $4 \mathrm{~h} 39$ \\
Specific surface $\left(\mathrm{m}^{2} \cdot \mathrm{kg}^{-1}\right)$ & 315.50 \\
Expansion $\left(10^{-3} \mathrm{~m}\right)$ & 1.50 \\
Refusal on sieve 0.08 & 10.92 \\
Refusal on sieve 0.16 & 0.80 \\
\hline
\end{tabular}

Table 2: Cement chemical characteristics (NOCIBE laboratory, NF EN 197-1: 2012)

\begin{tabular}{lc}
\hline Designation & Value (\%) \\
\hline $\mathrm{SiO}_{2}$ & 17.16 \\
$\mathrm{Al}_{2} \mathrm{O}_{3}$ & 5.10 \\
$\mathrm{Fe}_{2} \mathrm{O}_{3}$ & 2.61 \\
$\mathrm{CaO}$ & 60.55 \\
$\mathrm{MgO}$ & 1.76 \\
$\mathrm{SO}_{3}$ grav & 2.50 \\
$\mathrm{Res}$. Insoluble & 1.40 \\
Fire loss & 9.85 \\
\hline
\end{tabular}

\section{Cement}

The cement used is CPJ 35 type from New Cement Company of Benin (NOCIBE). Its compressive strength is $33 \mathrm{MPa}$ at $28^{\text {th }}$ day. Tables 1 and 2 show respectively cement physical and chemical characteristics. These caracteristics werre provieded by NOCIBE laboratory.

\section{Materials Formulation}

Absolute and real volume methods were used for samples formulation. These methods consist of:

- Fixing cement dosage at $250 \mathrm{~kg} \cdot \mathrm{m}^{-3}$. This dosage is cement mass contained in $1 \mathrm{~m}^{3}$ of fresh concrete;

- Choosing mixing water to cement dosage ratios suitable for workability of fresh mixture by a workability test of composites, using Eq. (1). In this study, this ratio is 0.8 in order to obtain a good consistancy of material;

- Defining aggregates mass (millet pods fibers and laterite gravel) necessary for implementation of $1 \mathrm{~m}^{3}$ of mix, using Eq. (2);

- Determining fibers mass by partially substituting lateritic gravel mass by 2, 4 and $6 \%$ of millet pods fibers in the control mixture to obtain fiber mortars:

$K=\frac{W}{C}=\frac{\text { Water masse }}{\text { cement mass }}$

$V_{L G}=1-\left(\frac{C}{\rho_{\text {cement }}}+k \frac{C}{\rho_{\text {water }}}\right)$

\section{Mixing Procedure is as Follows}

First introduce water into mixer takn then pour in cement. 


\section{Stard Mixer at Low Speed}

After mixing for $30 \mathrm{~s}$, regularly introduce millet pods and laterite gravel for $30 \mathrm{~s}$. Then put mixer at high speed and continue mixing for an additional $30 \mathrm{~s}$.

Stop mixer for $1 \mathrm{~min} 30 \mathrm{~s}$. During first $15 \mathrm{~s}$ remove with a rubber scraper all mortar adhering to walls and bottom of container by pushing it toward middle of it.

\section{Then Resume Mixing at High Speed for $60 \mathrm{~s}$}

After mixing until homogeneous mixture is obtained, samples were molded in two metal presses of size : $(4 \times 4 \times$ 16) $\mathrm{cm}^{3}$ for porosity tests and $(4 \times 4 \times 5) \mathrm{cm}^{3}$ for thermal tests (Fig. 4). To ensure proper implementation without a risk of segregation of lightweight concrete, a slight vibration was made so that the lightweight aggregates do not rise to surface if too much vibration is produced. To avoid this problem, we performed the mixing sample by sample and finally compaction using the press to allow uniform compaction of layers. After that press is leveled and stored in laboratory for $24 \mathrm{~h}$. Table 3 shows materials mass composition.

\section{Composite Physical Characterization}

Physical tests were based on density ; humidity rate; absorption rate and porosity determination.

\section{Density}

Density had been determined according to Norme NF EN 1097-6 (2014) standard. Figure 5 shows composites densities as a function of age.

Summary graph analysis shows that more millet bean fibers there are in the sample, more density decreases and depends on specimen age. The low density of millet pods fibers in composites induces a reduction in their density compared to that of control composite. As sample approaches maturity, its density decreases regardless of specimen type. Density therefore decreases with increase in fibers percentage and this over time. Millet pods fibers presence in a test tube decreases its density. This confirms results of $\mathrm{Bal}$ who worked on modeling and measuring thermal properties of a wet porous medium: Laterite brick with millet pods Nadia (Bal, 2011; Makhlouf, 2010).

\section{Humidity}

This is the ratio of difference in initial and steamed sample mass to its initial mass. Figure 6 shows composites humidity.

From Fig. 6 analysis, it emerges that more millet pod fibers there are in sample, more moisture level increases but decreases with specimen age. Millet pod fibers presence in composites causes pores to appear unlike control composite. As sample approaches maturity, moisture content becomes less and less important. This is due to moisture evaporation from specimen. The humidity level therefore increases with increase in fibers percentage but decreases over time regardless of test specimen type. This confirms results of Bal (2011) who worked on modeling and measuring thermal properties of a wet porous medium : Laterite brick with millet pod and those of Bal (2011); Baley (2005).

\section{Porosity}

The porosity was determined according to NF P 18 554, (1990) and NF EN 1097-3, (1998) standards.

Figure. 7 analysis shows a clear difference in ET, G2, G4 and G6 composite porosities. Samples porosities vary from 0.13 to 0.46 depending on composite type. From these observations, it clearly appears that more mixture contains millet pods fibers, more porous it is. More fiber elements mixture contains, more void it has, which influences its porosity. This confirms results of Meukam who worked on local materials characterization for buildings thermal insulation (Meukam et al., 2004).

Table 3: Composite mass composition (ET $=$ control sample without millet pods, $\mathrm{G} 2=2 \%$ millet pods, $\mathrm{G} 4=4 \%$ millet pods, $\mathrm{G} 6=$ $6 \%$ millet pods)

\begin{tabular}{lllll}
\hline Samples & Millet pods $(\%)$ & Gravel lateritic $(\%)$ & Cement $(\%)$ & $\frac{w}{c}$ \\
\hline ET & & & 26 & 0.8 \\
G2 & 0 & 74 & 26 & 0.8 \\
G4 & 4 & 70 & 26 & 0.8 \\
G6 & 6 & 68 & 26 & 0.8 \\
\hline
\end{tabular}

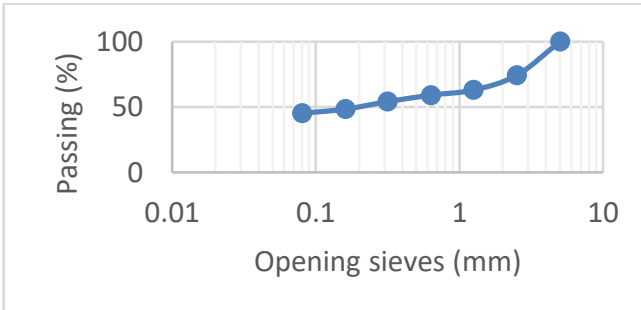

Fig. 1: Lateritic gravel granulometric analysis curve 
Djossou Ayihaou Armand et al. / American Journal of Engineering and Applied Sciences 2021, 14 (3): 398.408 DOI: 10.3844/ajeassp.2021.398.408

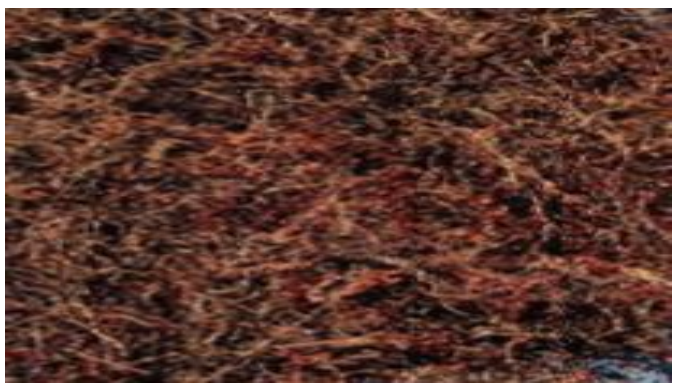

Fig. 2: Millet pods fibers texture

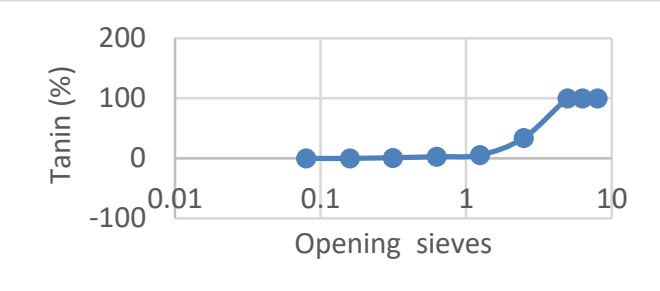

Fig. 3: Millet pods fibers granulometric analysis curve

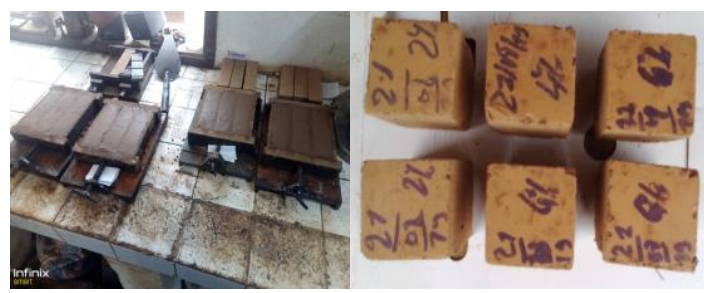

Fig. 4: Specimens molding and unmolding

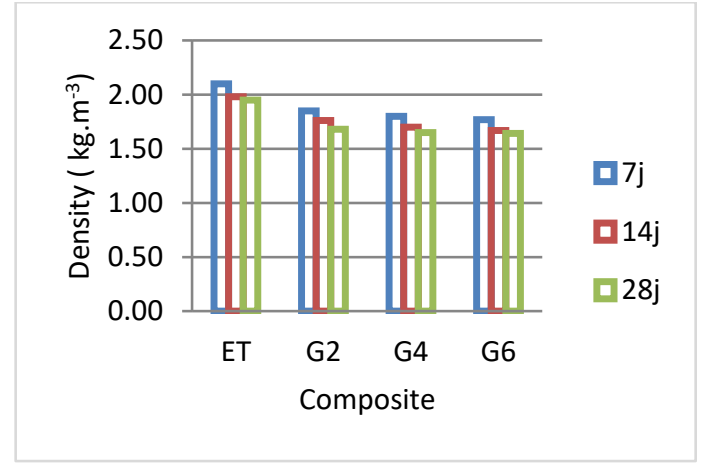

Fig. 5: Composites density

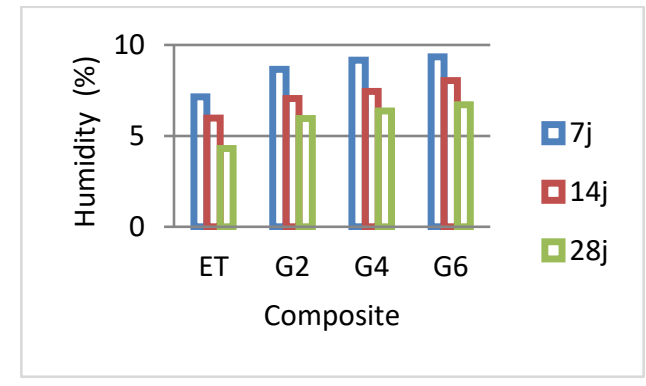

Fig. 6: Composites humidity 


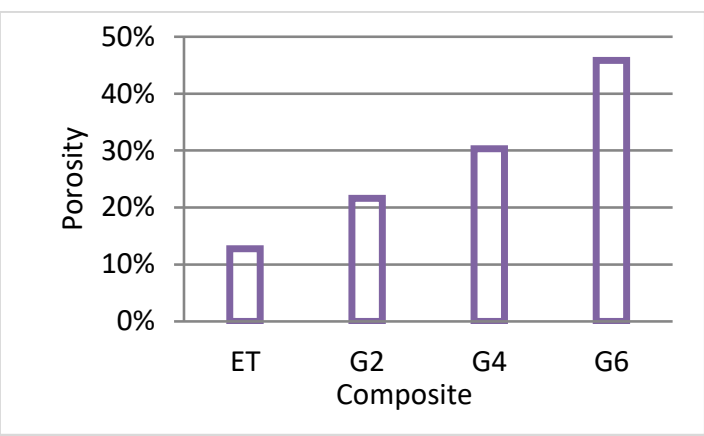

Fig. 7: Composite porosity at 28 days

\section{Composite Thermophysical Characterization}

Fluxmetric method used is similar to that of mini hot plate (Kaemmerlen, 2009). Its implementation consists in producing a temperature gradient according to sample thickness to be characterized and measuring heat flux which passes through it. Temperature difference between sample two faces is applied thanks to specifically sized thermos-elements. Heat flux is measured by thermopiles in accordance with ASTM, (2017); ISO 8301, (1991) and NF EN 12667, (2001) standards. Its implementation involves different elements calibration. In addition, experimental device has an affordable cost.

\section{Peltier Elements Calibration in Flux-Meter}

Peltier elements used are those of TEC1-12706 model and of $(4 \times 4 \times 0.4) \mathrm{cm}^{3}$ dimensions. There are different methods of calibrating or determining flux-meters sensitivity. The one used in this study is similar to that of (Oter-Duthoit, 1985; Güths, 1994). Figure 8 described experimental device.

\section{Steady State Flux-Meter Calibration}

When a voltage $U_{c}$ is applied to heating resistor terminals, there is a release of heat by Joule effect corresponding to heat flux given by Eq. (3):

$$
\varphi_{C}=\frac{U_{C}^{2}}{R_{C}{ }^{\prime}} \text { where } R_{C}=44 \Omega
$$

When steady state is established, voltage across heating element stabilizes at an equilibrium value Up. Calibrating Peltier element as a steady-state flux-meter consists of establishing $\varphi_{c}=f\left(U_{p}\right)$ curve. To do this, it suffices to note the $\mathrm{N}$ equilibrium values Upi corresponding to $\mathrm{N}$ different values of $U_{c i}$ voltage applied to heating resistor. Problem to be solved is therefore to find equation $\varphi_{c}=f\left(U_{p}\right)$ curve. Using Excel software, we determined regression line best representing $\mathrm{N}$ pairs of experimental points $\left(\varphi_{c i}, U_{c i}\right)$. In this case $\mathrm{N}=5$. Results obtained are respectively presented on Fig. 9, 10, 11 and 12. Correlation coefficients $\mathrm{R}^{2}$ provide information on trend curves precision order. Said curves show variation of heat flux passing through Peltier element as a function of voltage at its terminals. Direction coefficient of linear regression obtained for each Peltier element will be used to convert voltages measured at Peltier element terminals into heat flux.

\section{Fluxmetric Method Modeling}

Fluxmetric method has advantage of offering better repeatability for large specimens with less execution time (Mohaine $e t$ al., 2017). Consider a wall of $e$ thickness, of $S$ surface and made of a homogeneous material. Either $\varphi$ its density, $c$ specific heat and $\lambda$ thermal conductivity. The exterior face is subjected to a flux $\varphi(0, t)$ and a temperature $T(0, t)$ and a flux $\varphi(e, t)$ and a temperature $T(e, t)$ are collected on the interior face (Fig. 13a). Physically conceivable walls or walls are essentially of three types:

- purely capacitive walls or $\rho_{c}$ is largely predominant

- purely resistive walls or conductivity $\lambda$ is very small

- half-capacitive, half-resistive hybrid walls

The first two cases obey purely mathematical considerations and are encountered only very rarely in reality. This is why we are going to adopt for our study, a hybrid wall taking into account two previous cases and whose thermal behaviors can be deduced by simplifications of general case. The quadrupole diagram of a complete semiinfinite wall is presented in Fig. 13b.

A medium is said to be semi-infinite when it extends to infinity. From a thermal point of view, a wall will be considered semi-infinite when a stress occurring on one face has no repercussion on other. Preceding quadrupole diagram can be translated into Laplace domain (frequency domain) by Eq. (4):

$\Psi(0, \omega)=j \omega(\rho c e) \times \theta(0, \omega)$

Return to time domain (Laplace inverse transforme) is written through Eq. (5) and (6):

$\phi(t)=(\rho c e) \frac{d T(t)}{d t}+\frac{\lambda}{e}(t)+C^{t e}$ 


$$
\phi(t)=(\rho c e) \frac{d T(t)}{d t}+\frac{U}{S} T(t)+C^{t e}
$$

where, $U\left(W \cdot K^{-1}\right)$ is thermal wave transmition coefficient.

This model allows to process all thermal scenarios presented by our samples subjected to solar thermal stresses. In event that we do not have a response on sample inside face, outsides flux and temperature are data to be implemented in model.

If we have a response on material interior face, flux to be considered would be $\varphi=\varphi_{\text {ext }}-\varphi_{\text {int }}$ and temperature to be considered would be $T=T_{e x t}-T_{i n t}$ in this model implementation. Thus, for $\mathrm{N}$ couple observations we obtain following system of Eq. (7):

$$
\left[\begin{array}{c}
\phi\left(t_{1}\right) \\
\phi\left(t_{2}\right) \\
\cdot \\
\cdot \\
\cdot \\
\phi\left(t_{N}\right)
\end{array}\right]=\left[\begin{array}{ccc}
\frac{d T\left(t_{1}\right)}{d t} & T\left(t_{1}\right) & 1 \\
\frac{d T\left(t_{2}\right)}{d t} & T\left(t_{2}\right) & 1 \\
\cdot & \cdot & \cdot \\
\cdot & \cdot & \cdot \\
\frac{d T\left(t_{N}\right)}{d t} & T\left(t_{N}\right) & 1
\end{array}\right]\left[\begin{array}{c}
\rho c e \\
\frac{U}{S} \\
C^{t e}
\end{array}\right]
$$

Which can also be put in condensed form such as Eq. (8):

$$
\phi=X \beta
$$

where, $\phi$ denotes heat flux density vector observations, $\beta$ parameters to be estimated vector and $X$ sensitivity matrix to parameter vector $\beta$. At this stage, when certain conditions are met, namely:

- The exact value $\phi_{0}$ of $\phi$ is known with an error of zero mean and constant standard deviation (there is no correlation between $\mathrm{N}$ measurements)

- The sensitivity matrix $X$ is known without measurement noise then under these conditions, Gauss Markov theorem ensures that optimal estimator of parameter vector $\beta$, that is to say of minimum covariance matrix, is given by Linear Least Squares estimator through Eq. (9):

$$
\hat{\beta}=\left(X^{T} X\right)^{-1} X^{T} \phi
$$

The optimum parameter $\hat{\beta}$ can thus be calculated from measured temperature with $\mathrm{K}$ thermocouples type and flux density data. Heat capacity $\rho c$ and transfer coefficient $U$ of each of samples subjected to study can be obtained in this way. In context of this study, this estimate was made with a Matlab program. Figure 14 shows experimental device.

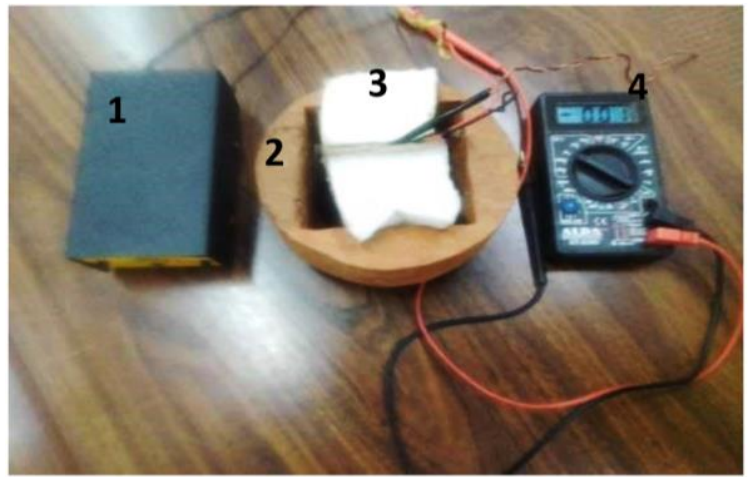

Fig. 8: Experimental device calibration (1-stabilized supply; 2-clamping device; 3 -Polystyrene $(1.5 \mathrm{~cm})+$ paper binder box + heating element + Peltier element + strap binder box + polystyrene; 4 -multimeter)

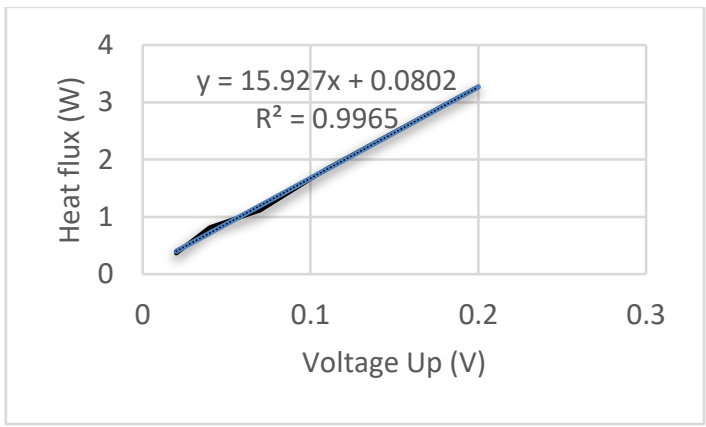

Fig. 9: $1^{\text {st }}$ Peltier element calibration trend curve: $\alpha_{1}=15.927$ V.W $\mathrm{W}^{-1}$ 
Djossou Ayihaou Armand et al. / American Journal of Engineering and Applied Sciences 2021, 14 (3): 398.408 DOI: 10.3844/ajeassp.2021.398.408

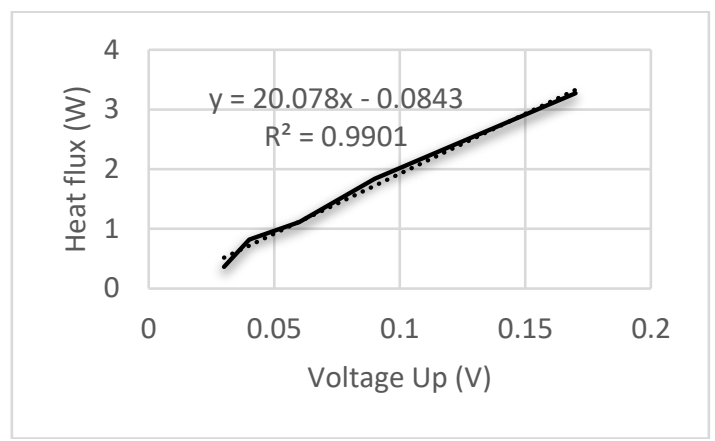

Fig. 10: $2^{\text {nd }}$ Peltier element calibration trend curve: $\alpha 2=20.078$ V.W $\mathrm{W}^{-1}$

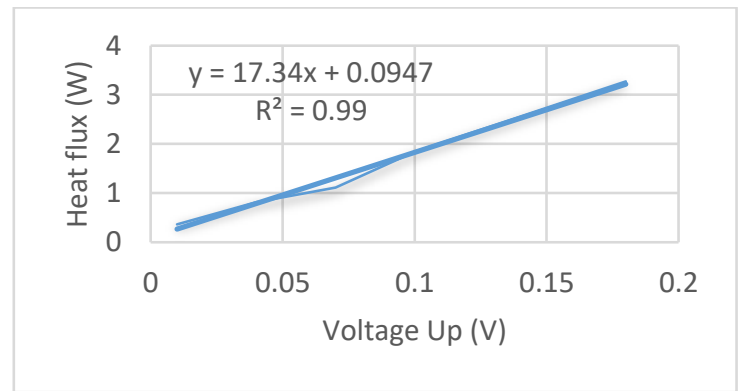

Fig. 11: $3^{\text {rd }}$ Peltier element calibration trend curve: $\alpha_{3}=17.34$ V.W $\mathrm{W}^{-1}$

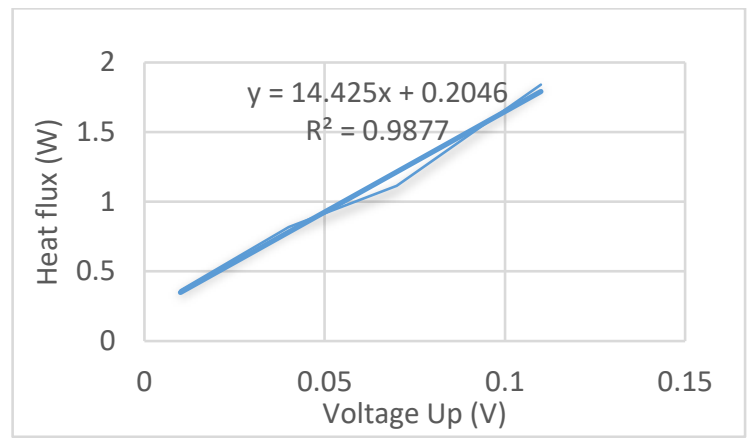

Fig. 12: $4^{\text {th }}$ Peltier element calibration trend curve: $\alpha_{4}=14.425 \mathrm{~V} \cdot \mathrm{W}^{-1}$

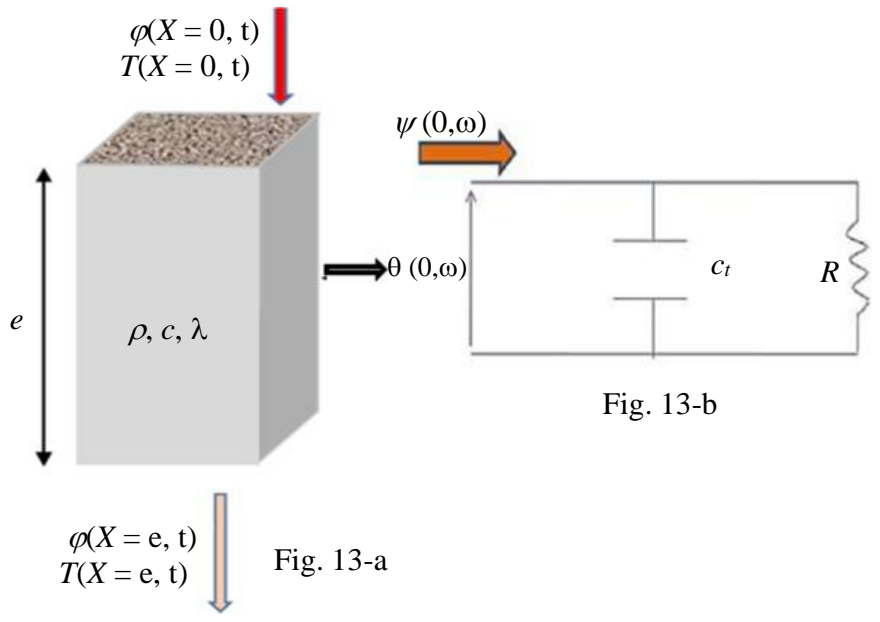

Fig. 13: Quadrupole diagram of complete semi-infinite medium 


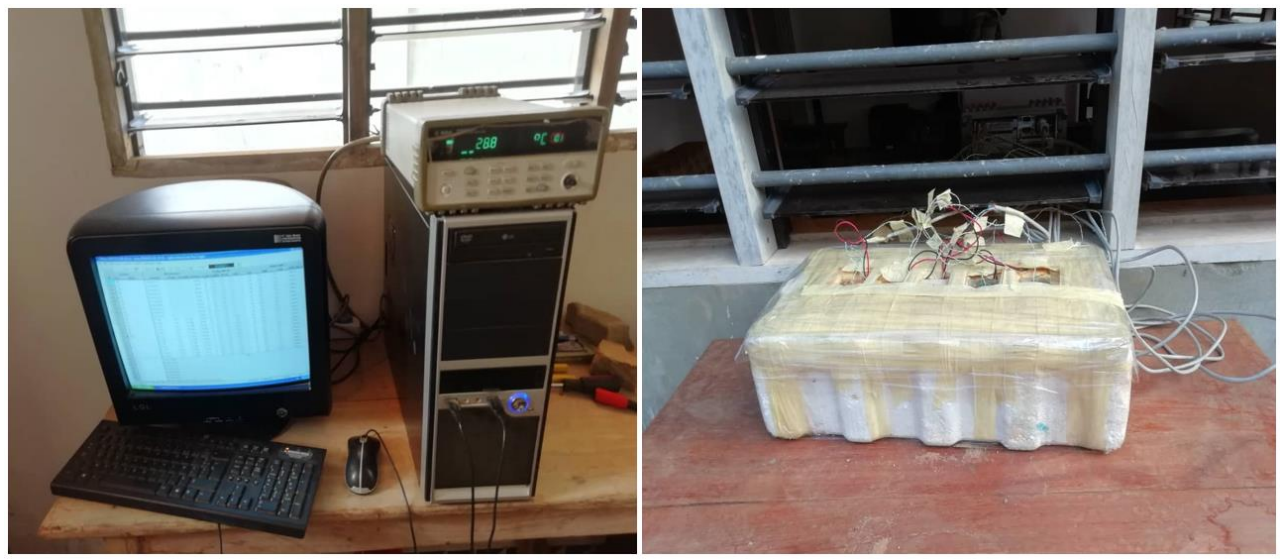

Fig. 14: Fluxmetric method experimental device

\section{Results and Discussion}

Each thermal tests duration is $24 \mathrm{~h}$ i.e., one day. Each thermophysical characteristic presented is therefore average of 5 tets carried out in same conditions over 5 days. As example, tables 4 and 5 show all thermal conductivity and effusivity obtained during 5 days of experimentation with standard deviations. Low standard deviations values confirm good prcision and reproducibility of results. Figures 15-19 show thermophysical properties of characterized eco-concrete.

\section{Thermal Conductivity}

Figure 15 analysis shows that when millet pods rate increases from 0 to $6 \%$, composite thermal conductivity decreases from $1.18 \mathrm{~W} \cdot \mathrm{m}^{-1} \cdot \mathrm{K}^{-1}$ to $0.61 \mathrm{~W} \cdot \mathrm{m}^{-1} \cdot \mathrm{K}^{-1}$, i.e., a reduction of $93.44 \%$. It therefore follows that millet pod rate increase resulted composite insulating capacity improvement. This result is justified by porosity increase due to millet pods fibers. Same observation has been noted compared to Bal (2011) on laterite containing millet pods and those of Meukam et al. (2004) on stabilized laterite incorporating sawdust. Millogo et al. (2014) work on stabilized earth bricks incorporating kenaf fibers yielded similar results. Djossou et al. (2018 and 2020) showed that cow dung or banana fibers addition to stabilized laterite with cement produced composite of thermal conductivity in range $1.3-0.453 \mathrm{~W} \mathrm{~m}^{-1} \mathrm{~K}^{-1}$. Therefore, millet pods fibers would improve thermal comfort by reducing concrete thermal conductivity.

\section{Thermal Effusivity}

Figure 16 also shows thermal effusivity values reduction from $2157.33 \mathrm{~J} \cdot \mathrm{m}^{-1} \cdot \mathrm{K}^{-1} \cdot \mathrm{s}^{-0.5}$ to 775.04 $\mathrm{J} . \mathrm{m}^{-1} \cdot \mathrm{K}^{-1} \cdot \mathrm{s}^{-0.5}$, i.e., reduction of $64.07 \%$ when millet pod rate increases from 0 to $6 \%$.

Thermal effusivity characterizes material ability to exchange heat with its environment. It characterizes heat or cold sensation given by matérial. Higher effusivity value, faster material absorbs a lot of heat without significantly heating up on surface (Ouedraogo et al., 2015). Conversely, a low effusivity value indicates that material heats up fastly on surface by absorbing little heat.

We therefore retain from results obtained analysis that more millet pod content increases (from 0 to 6\%), more tested composite heats up on surface by absorbing little heat. In tropical country such as Benin, heat usually passes through building envelope from outside to inside. Same observation has been noted compared to Djossou et al. (2018 and 2020) on stabilized laterite with cement incorporating cow dung or banana fibers which thermal effusivity varie from $2936,220 \mathrm{~J} \cdot \mathrm{m}^{-2} \cdot \mathrm{K}^{-1} \cdot \mathrm{s}^{-0.5}$ to $1608,530 \mathrm{~J} \cdot \mathrm{m}^{-2} \cdot \mathrm{K}^{-1} \cdot \mathrm{s}^{-0.5}$ and from $1755,828 \mathrm{~J} \cdot \mathrm{m}^{-2} \cdot \mathrm{K}^{-1} \cdot \mathrm{s}^{-0.5}$ to $1100,267 \mathrm{~J} \cdot \mathrm{m}^{-2} \cdot \mathrm{K}^{-1} \cdot \mathrm{s}^{-0.5}$. Consequently, effusivity reduction observed from 2157.33 $\mathrm{J} \cdot \mathrm{m}^{-1} \cdot \mathrm{K}^{-1} \cdot \mathrm{s}^{-0.5}$ to $775.04 \mathrm{~J} \cdot \mathrm{m}^{-1} \cdot \mathrm{K}^{-1} \cdot \mathrm{s}^{-0.5}$ shows that a wall based on tested composite will offer more thermal comfort inside building by opposing thermal resistance to heat transfer from outside to inside.

\section{Thermal Diffusivity}

Unlike thermal conductivity and effusivity, Fig. 17 analysis shows thermal diffusivity increase from $3.00 \cdot 10^{-7} \mathrm{~m}^{2} . \mathrm{s}^{-1}$ to $6 \cdot 25 \cdot 10^{-7} \mathrm{~m}^{2} \cdot \mathrm{s}^{-1}$. This result shows that millet pods fibers cause an increase of heat diffusion rate through composite, nevertheless, values obtained are close to Meukam results on stabilized laterite incorporating sawdust (Meukam et al., 2004).

\section{Thermal Phase}

Figure 18 shows thermal phase increase from $61.00 \mathrm{~min}$ to $84.20 \mathrm{~min}$ (i.e., $1.016 \mathrm{~h}-1.403 \mathrm{~h}$ ) with a thickness of $5 \mathrm{~cm}$. As a result, more plant fiber (millet pods) in test tube, less time it takes to transfer heat flux through material. This result shows that millet pod fibers better delay thermal wave transmission through characterized material. 
It therefore characterizes material's ability to delay temperature variations. Higher thermal phase, better thermal comfort because outside temperature variations are felt much less quickly inside. Thermal phase obtained were slightly less than $2.51 \mathrm{~h}$ and 3.32 h obtained by Djossou et al., (2017) and Obahoundje et al., (2018), probably due to small samples thickness of $5 \mathrm{~cm}$. Material thickness increase leads to higher thermal phase.

\section{Thermal Damping}

Figure 19 shows thermal damping increase from 5.43 to $13.18 \%$. This observation indicates that millet pods fibers attenuate thermal wave amplitude and therefore may limit heat losses and thus contribute energy saving in building.

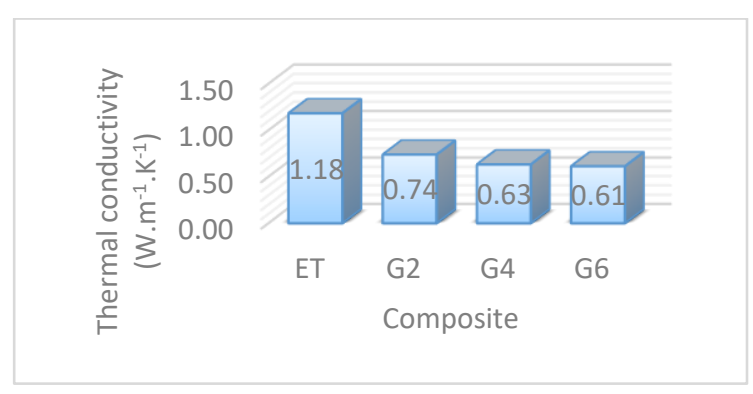

Fig. 15: Composite thermal conductivity

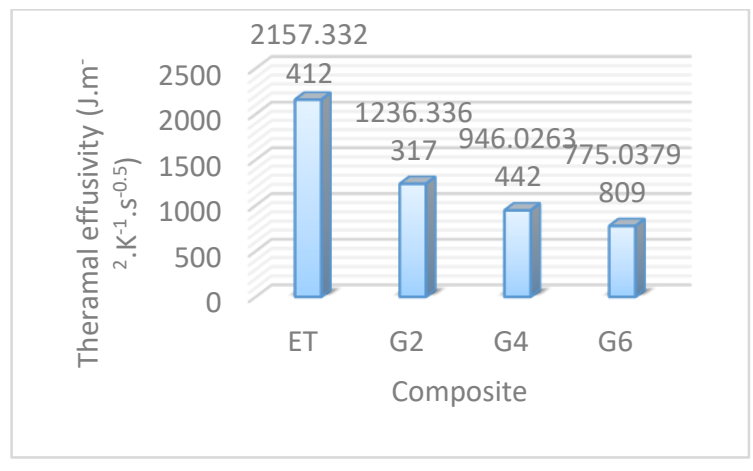

Fig. 16: Composite thermal effusivity

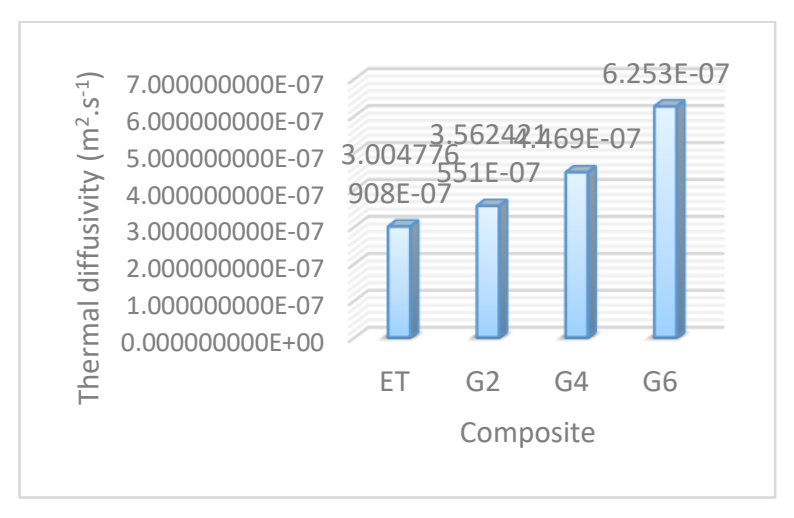

Fig. 17: Composite thermal diffusivity

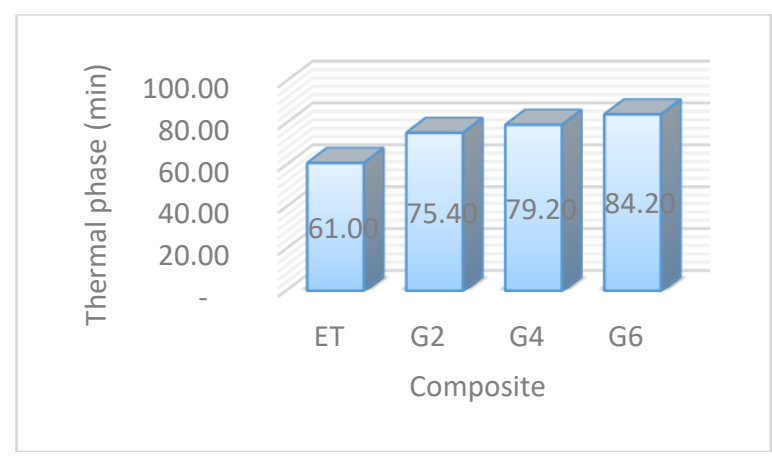

Fig. 18: Composite thermal phase

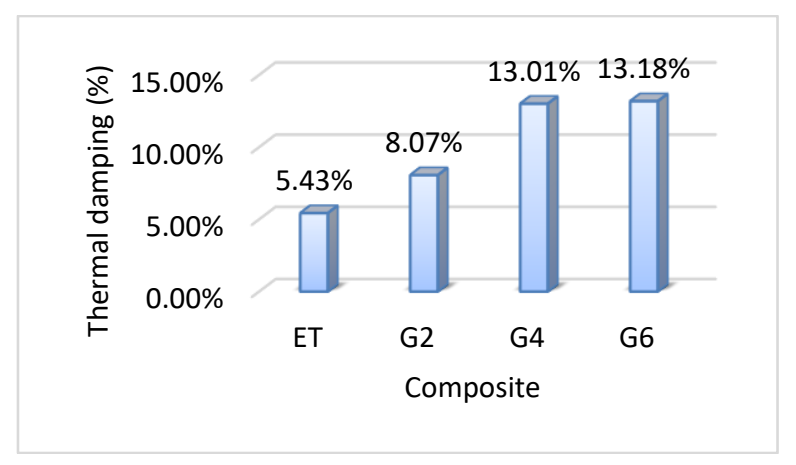

Fig. 19: Composite damping

Table 4: Thermal conductivity precision

\begin{tabular}{|c|c|c|c|c|}
\hline \multicolumn{5}{|c|}{ Thermal conductivity $\left(\mathrm{W} \cdot \mathrm{m}^{-1} \cdot \mathrm{K}^{-1}\right)$} \\
\hline Day & ET & G2 & G4 & G6 \\
\hline $1^{\text {st }}$ day & 1.20 & 0.745 & 0.645 & 0.580 \\
\hline $2^{\text {nd }}$ day & 1.24 & 0.750 & 0.660 & 0.650 \\
\hline $3^{\text {rd }}$ day & 1.16 & 0.720 & 0.635 & 0.640 \\
\hline $4^{\text {th }}$ day & 1.10 & 0.745 & 0.595 & 0.560 \\
\hline $5^{\text {th }}$ day & 1.20 & 0.740 & 0.615 & 0.620 \\
\hline Average & 1.18 & 0.740 & 0.630 & 0.610 \\
\hline Standard deviation & 0.05 & 0.010 & 0.030 & 0.040 \\
\hline
\end{tabular}


Table 5: Thermal effusivity precision

\begin{tabular}{|c|c|c|c|c|}
\hline \multicolumn{5}{|c|}{ Thermal effusivity $\left(\mathrm{J} \cdot \mathrm{m}^{-2} \cdot \mathrm{K}^{-1} \cdot \mathrm{s}^{-0.5}\right)$} \\
\hline Day & ET & G2 & G4 & G6 \\
\hline $1^{\text {st }}$ day & 2170.10 & 1234.40 & 958.60 & 760.00 \\
\hline $2^{\text {nd }}$ day & 2225.35 & 1240.60 & 966.15 & 802.10 \\
\hline $3^{\text {rd }}$ day & 2080.30 & 1229.20 & 941.00 & 787.70 \\
\hline $4^{\text {th }}$ day & 2140.30 & 1230.10 & 920.30 & 750.20 \\
\hline $5^{\text {th }}$ day & 2170.60 & 1247.40 & 944.10 & 775.20 \\
\hline Average & 2157.33 & 1236.34 & 946.03 & 775.04 \\
\hline Standard deviation & 52.89 & 7.65 & 17.71 & 20.83 \\
\hline
\end{tabular}

\section{Conclusion}

The main objective of this study is to produce a lightweight composite concrete based on millet pods and lateritic gravel with a cement matrix for use in buildings to help improve thermal comfort and protect environment.

We retain from results obtained that moderate millet pods quantity incorporation in laterite stabilized with cement makes it possible to obtain a less dense and more porous eco-material. For millet pod content varying form 0 to $6 \%$, density at 28 days decreases from $1.95 \mathrm{~kg} . \mathrm{m}^{-3}$ to $1.64 \mathrm{~kg} \cdot \mathrm{m}^{-3}$ while porosity increases from 13 to $46 \%$.

It was also observed with a moderate millet pod quantity of $6 \%$, a reduction of $93.44 \%$ for thermal conductivity, $64.07 \%$ for thermal effusivity followed by increase of thermal diffusivity (from $3.00 .10^{-7} \mathrm{~m}^{2} \cdot \mathrm{s}^{-1}$ to $6.25 .10^{-7} \mathrm{~m}^{2} \cdot \mathrm{s}^{-1}$ ), thermal phase (from $61.00 \mathrm{~min}$ to $84.20 \mathrm{~min}$ ) and thermal damping (from 5.43 to $13.18 \%$ ).

Low standard deviations obtained from thermal tests repeated 5 times in same conditions prove results reliability and reproducibility.

All of these results show that low density of millet pod-based composites positively influences material thermo-physical properties. Characterized eco-concrete could so be used as insulating material in building for improving thermal comfort on one hand and on other hand, for environment safeguard.

Results obtained through this study could be reinforced by other complementary studies taking into account material humidity variations influence on its thermophysical properties and on its mechanical compressive strength.

It could also be useful to study effective diffusion coefficient impact on chemical degradation of eco-concrete developed.

\section{Author's Contributions}

Djossou Ayihaou Armand: Participated in all thermal experiments, data-analysis and interpretation and writing of the manuscript.

Doko Kouandété Valéry: Participated in physical characterization of samples.
Wade Doukago Yacoubou Soumanou and Michozounnou N. Benoît: Participated in collection of raw materials and in samples manufacture.

Vianou Antoine: Designed the research plan and organized the study, contributed in article reviewing, Director of Labo CTMAE.

\section{Ethics}

This article is original and contains unpublished material. The corresponding author confirms that all of the other authors have read and approved the manuscript and no ethical issues involved

\section{References}

AsTerre. (2021). La technique du torchis. http://www.asterre.org/construire-en-terre. Consulté le 18-06-2021.

ASTM. (2017). Standard Test Method for Steady-State Thermal Transmission Properties by Means of the Heat Flow Meter Apparatus. American Society for Testing and Materials.

Aymerich, F., Fenu, L., \& Meloni, P. (2012). Effect of reinforcing wool fibres on fracture and energy absorption properties of an earthen material. Construction and Building Materials, 27(1), 66-72. https://doi.org/10.1016/j.conbuildmat.2011.08.008

Bal, H. M. (2011). Modeling and measurement of thermal properties of a wet porous medium: laterite brick with millet pod. Dakar: Ecole Supérieure Polytechnique de Dakar, 153.

Baley, C. (2005). Fibres naturelles de renfort pour matériaux composites. Ed. Techniques Ingénieur.

Dewulf, M. (2015). Le torchis, mode d'emploi: Connaître la terre crue-Interpréter les désordres-Organiser le chantier-Restaurer et protéger le torchis. Editions Eyrolles.

Djossou, A. A., Houehanou, E., Houngan, A. C., Ayena, V., \& Vianou, A. (2017). Thermal effusivity, thermal conductivity and compressive strength of cement stabilized laterites blended with cow dung. Journal of Applied Science \& Technology, 22. 
Djossou, A. A., Houngan, A. C., Awanto, C., Anjorin, M., \& Vianou, A. (2014). Effects of water and sawdust additives on thermal effusivity, thermal conductivity and durability of cement-stabilized laterites. Journal of Applied Science \& Technology, 19.

Djossou, A. A., Houngan, C.A., Houehanou, E., Vianou, A. (2020). Comparative study of the thermal behavior of stabili- zed soil incorporating cow dung and banana stem fibers, Intern. Symposium on Sci. \& Technol., October 14 to 18, 2019, Ouagadougou, Burkinabè Journal of research, Issue No. 5.

Güths, S. (1994). Anémomètre à effet Peltier et fluxmètre thermique: conception et réalisation, application à l'étude de la convection naturelle (Doctoral dissertation, Artois).

ISO 8301. (1991). Isolation thermique - détermination de la résistance thermique et des propriétés connexes en régime stationnaire - méthode flux-métrique. le dernier examen de cette norme date de 2019.

Kaemmerlen, A. (2009). Transfert de chaleur à travers les isolants thermiques du bâtiment (Doctoral dissertation, Université Henri Poincaré-Nancy 1).

Makhlouf, N. (2010). Caractérisation en statique du comportement en traction directe du béton armé de fibres en copeaux (Doctoral dissertation, Université Mouloud Mammeri).

Meukam, P., Jannot, Y., Noumowe, A., \& Kofane, T. C. (2004). Thermo physical characteristics of economical building materials. Construction and Building Materials, 18(6), 437-443. https://doi.org/10.1016/j.conbuildmat.2004.03.010

Millogo, Y., Morel, J. C., Aubert, J. E., \& Ghavami, K. (2014). Experimental analysis of Pressed Adobe Blocks reinforced with Hibiscus cannabinus fibers. Construction and Building Materials, 52, 71-78. https://doi.org/10.1016/j.conbuildmat.2013.10.094.

Mohaine, S., Grondin, F., Rougui, M., \& Loukili, A. (2017). Développement d'une méthodologie pour la mesure de la conductivité thermique des mortiers par la méthode fluxmétrique. Academic Journal of Civil Engineering, 35(1), 264-267.

https://journal.augc.asso.fr/index.php/ajce/article/vie w/ajce.35.1.64.

NF EN 197-1 (2012). Ciment - Partie 1: compositions, specifications, et critères de conformité des ciments courants.
NF EN 1097-3. (1998). Essais pour déterminer les caractéristiques mécaniques et physiques des granulats - Partie 3 : Détermination de la Masse volumique apparente. AFNOR.

NF EN 12667. (2001). Performance thermique des matériaux et produits pour le bâtiment Détermination de la résistance thermique par la méthode de la plaque chaude gardée et la méthode fluxmétrique - Produits de haute et moyenne résistance thermique. 01 juillet.

NF P 18 554. (1990). Granulats - Mesures des masses volumiques, de la porosité, du coefficient d'absorption et de la teneur en eau des gravillons et cailloux.

Norme NF EN 1097-6. (2014). Essais pour determiner les caractéristiques mécaniques et physiques des granulats-Partie 6: détermination de la masse volumique réelle et du coefficient d'absorption d'eau.

Obahoundje, S., Houngan, C. A., Djossou, A. A., Djikou, S. M., Anjorin, M., Vianou A. (2018). Literature review on the influence of thermal inertia of local building materials on the thermal comfort of occupants: Case of Benin, CIFEM2018-ART-3-14. 2018.

Oter-Duthoit, L. (1985). Application des méthodes de la théorie des systèmes à la simulation de l'évolution des flux thermiques sur les faces d'entrée et de sortie d'une paroi multicouche (Doctoral dissertation, Lille 1). https://www.theses.fr/1985LIL10062

Ouedraogo, E., Coulibaly, O., Ouedraogo, A., \& Messan, A. (2015). Mechanical and thermophysical characterization of compressed earth blocks stabilized with paper (cellulose) and / or cement. Journal of Materials and Engineering Structures, 2, 68-76. https://docplayer.fr/21892099-Caracterisationmecanique-et-thermophysique-des-blocs-de-terrecomprimee-stabilisee-au-papier-cellulose-et-ou-auciment.html

Phung, T. A. (2018). Formulation et caractérisation d'un composite terre-fibres végétales: la bauge (Doctoral dissertation, Normandie Université). https://tel.archives-ouvertes.fr/tel-01938827/

Röhlen, U., Ziegert, C., \& Mochel, A. (2013). Construire enterre crue: Construction, rénovation, finitions (p. 1). Editions Le Moniteur. https://catalogue-bu.u-

bourgogne.fr/discovery/fulldisplay/alma9910054344 79706659/33UB_INST:33UB_INST 